\title{
Luciana no espelho: representações do corpo com deficiência física na telenovela viver a vida
}

\author{
Luciana in the mirror: representations of the body with physical disabi- \\ lities in the soap opera viver a vida
}

http://dx.doi.org/10.5007/2178-4582.2014v48n1p75

\author{
Melina de la Barrera Ayres, Carmen Silvia Rial e Adriano Henrique Nuernberg \\ Universidade Federal de Santa Catarina, Florianópolis/SC, Brasil
}

\begin{abstract}
As interpretações sobre o corpo são construídas a partir de múltiplas relações sociais, sendo que atualmente a mídia é um elemento muito presente nestas relações. Dentre os discursos da mídia no Brasil, as telenovelas têm grande destaque, tendo se tornado um espaço público de discussão. A partir desse entendimento, este artigo discute as representações do corpo com deficiência física na telenovela Viver a Vida (Manoel Carlos, Rede Globo; 2009). A análise parte da perspectiva etnográfica e cinematográfica, aplicando a etnografia de tela, e se apoia nos disability studies e nos estudos de gênero. A análise permite verificar a complexidade desta abordagem, e o diálogo estabelecido entre a ficção e a Convenção sobre os Direitos das Pessoas com Deficiência. Esta análise faz parte da pesquisa que está sendo desenvolvida desde 2011, no Doutorado Interdisciplinar em Ciências Humanas da Universidade Federal de Santa Catarina.
\end{abstract}

Palavras chaves: Corpo - disability studies - representação - telenovela.
The interpretations of the body are built from multiple social relations, whereas currently the media is a very present element in these relationships. Among the discourses of the media in Brazil, soap operas have great prominence, having become a public space for discussion. Based on this understanding, this paper discusses the representations of the body with physical disabilities in the soap opera Viver a Vida (Manoel Carlos, Rede Globo, 2009). The analysis starts from the ethnographic and cinematic perspective, applying ethnography of screen, and is based on disability and gender studies. The analysis shows the complexity of this approach, and the dialogue established between fiction and the Convention on the Rights of Persons with Disabilities. This analysis is part of a research that is under development since 2011, in an Interdisciplinary PhD Program in Humanities at the Federal University of Santa Catarina.

Keywords: Body - disability studies - representation - soap opera.

\section{Introdução}

“A existência do homem é corporal” disse David Le Breton (2011, p. 10, tradução nossa), ao explicar que sem um corpo, sem um rosto, o ser humano não existiria. $\mathrm{O}$ corpo é o mediador entre cada um de nós e o mundo, entre o 'eu' e o 'outro'. O corpo, constituído de inúmeras características - cor, estatura, peso, sexo, idade, etc.-, é constantemente interpelado, 'classificado', 'diferenciado' social e culturalmente, a partir delas.

A noção de corpo responde, entre outras coisas, à visão de mundo de cada sociedade. O modo como, atualmente, as sociedades ocidentais entendem o corpo é resultado de uma longa construção histórica. De acordo com Le Breton "o corpo é entendido por nossas sociedades como o lugar do sujeito, de 
seu limite, de sua diferença e de sua liberdade" (Ibid., p. 20, tradução nossa). Para este autor, a noção moderna de corpo é individualista, pois rompe com a solidariedade do coletivo, marcada pelo fechamento do sujeito sobre si mesmo.

$\mathrm{Na}$ deficiência física o corpo é o principal marcador da diferença (BRAH, 2006). Sobre esse corpo são criadas diversas representações voltadas à perspectiva incapacitante. Essas interpretações são construídas ao longo do tempo a partir de múltiplas relações sociais. Nos dias de hoje um dos elementos integrantes dessas relações são os meios massivos de comunicação, que fazem parte da cultura e são centrais na construção de sentidos. Portanto, cabe a pergunta: como o corpo com deficiência física é representado pela mídia? Buscando apontar algumas respostas a esta questão, este texto discute a abordagem do corpo com deficiência física na telenovela. Este tipo de produção, apesar de ser fundamentalmente ficcional, devido à sua grande audiência e ao seu estilo narrativo, transforma-se em espaço público de discussão, expondo problemas sociais, gerando controvérsias e incentivando mudanças. Nesta perspectiva Almeida afirma que "[...] as novelas promovem um processo de reflexão e revisão das representações" (2003, p. 41).

Por conseguinte, a pergunta norteadora deste trabalho é: quais são as representações do corpo com paraplegia apresentadas na telenovela Viver a Vida? Esta telenovela escrita por Manoel Carlos, produzida e transmitida pela Rede Globo em 2009, conta a história de Luciana, uma jovem modelo que fica paraplégica após um acidente de trânsito. A telenovela foi veiculada pouco tempo depois da entrada em vigor da Convenção sobre os Direitos das Pessoas com Deficiência, ratificada pelo Congresso Nacional em julho de 2008. A Convenção garante os direitos básicos das pessoas com deficiência em equiparação de oportunidades aos serviços de saúde, reabilitação, educação, profissionalização, esporte, cultura e lazer.

A abordagem da temática teve ainda outro diferencial na história da teledramaturgia brasileira: a deficiência não foi apresentada como uma 'punição' para a personagem.

\section{Perspectiva teórica - um olhar sobre o corpo}

A interpretação do corpo com deficiência que esteve mais presente ao longo dos séculos é aquela que se refere à perspectiva biomédica, que estabelece um 'padrão de normalidade ou anormalidade' e confina a deficiência à presença de uma lesão.

Esse entendimento, ligado à concepção do corpo como máquina, perspectiva surgida a partir do pensamento de Descartes, propõe a inteligibilidade mecanicista, que faz da matemática a chave para compreender a natureza e o homem (LE BRETON, 2011). Deste modo, sendo o corpo uma máquina, ele possui uma estrutura estável dividida em partes, que, para funcionar corretamente, podem/devem ser ajustadas quando for necessário. 
Assim, o saber biomédico deve trabalhar para corrigir, normalizar, todo corpo que possui uma estrutura comprometida, insuficiente, limitada. Por conseguinte, a partir desta perspectiva, o corpo com deficiência é entendido como aquele que sofreu/sofre perdas, anormalidades permanentes ou transitórias, restrições ou impedimento na realização de atividades, ou limitações no cumprimento de funções consideradas 'comuns' de acordo a idades, sexos e fatores socioculturais. Esta é a concepção biomédica do corpo, formalizada em 1980 pela Organização Mundial da Saúde (OMS), através da Classificação Internacional de Deficiências, Incapacidades e Desvantagens (CIDID), e que hoje se contrapõe ao modelo social, na Classificação Internacional de Funcionalidade, Incapacidade e Saúde (CIF) proposta pela mesma organização em 2001.

Este modelo compreende, ainda, o corpo como um padrão: todas as máquinas são e devem ser iguais, e a medicina despersonaliza as doenças: "a doença é uma intrusa que surge de problemas mecânicos" (Ibid., p.110, tradução nossa). Este modo de entender o corpo acarreta algumas consequências. Por um lado, quem está 'fora desse padrão de normalidade' é marginalizado pela sociedade. No dizer de Le Breton, a partir deste entendimento, a pessoa com deficiência "não é nem doente, nem saudável, nem morta, nem plenamente viva, nem fora da sociedade, nem incluída totalmente nela" (Ibid., p. 204, tradução nossa), ela é a prova da fragilidade da condição humana. Por outro lado, gradualmente a medicina negligencia o sujeito, sua história, seu meio social, suas experiências. A pessoa se torna invisível, o que importa para a medicina é a doença ou a lesão. Esta concepção médica, predominante na compreensão moderna do corpo, ultrapassa a medicina e se espalha por todos os âmbitos de nossa sociedade.

Opondo-se a esta perspectiva, surge na década de 1970, no Reino Unido, o modelo social da deficiência e seu campo de estudos acadêmicos, conhecido como disability studies. Este modelo parte da distinção entre lesão e deficiência. A lesão é consequência de uma doença ou impedimento, e a deficiência é uma experiência causada por um contexto pouco sensível à variação corporal humana. Considera-se a interação entre a lesão e o ambiente, sendo este fonte de barreiras que levam à experiência da deficiência. Com o modelo social, a deficiência não é compreendida como uma "tragédia pessoal", mas como uma forma de opressão social e um "estilo de vida", legítimo dentro das possibilidades humanas e inerente ao ciclo de vida (DINIZ, 2007; OLIVER, 2009).

Os disability studies entendem a deficiência como uma construção social e não como uma desigualdade natural, derivada de uma restrição funcional ou habilidade. Este questionamento do corpo como um dado natural que antecede a construção dos sujeitos é compartilhada também pelos estudos de gênero. No dizer de Ortega, "a dicotomia 'lesão/deficiência' é construída de maneira análoga à dicotomia 'sexo/gênero', sendo o primeiro um atributo biológico e o segundo, uma construção social" (2009, p. 68). Nesta construção, tanto as mulheres são compreendidas com "menor valor" em relação aos homens, 
como as pessoas com deficiência são entendidas com "menor valor", em relação as pessoas não deficientes. Esse valor é determinado inicialmente, pela diferença biológica, a distinção entre os 'padrões das máquinas definidas pela medicina', mas logo construído através dos discursos sociais.

Além destes pontos em comum, os estudos de gênero contribuíram com o modelo social ao refletirem sobre a importância do cuidado e a experiência do corpo com lesão. A primeira geração de pesquisadores e ativistas do modelo social eram homens, de classe média-alta, com lesões medulares, "apontados pelas teóricas feministas como membros da elite dos deficientes e, portanto, reprodutores dos discursos dominantes de gênero e classe na sociedade"(DINIZ, 2007, p.56). Este novo olhar trouxe ao campo a perspectiva da subjetividade e da trajetória individual da experiência da deficiência. De acordo com Diniz, “[...] o significado da transcendência do corpo para a experiência da dor, forçou uma discussão não apenas sobre a deficiência, mas sobre o que significa viver em um corpo doente ou lesado" (Ibid., p. 4).

Esta análise se embasará, portanto, na segunda geração do campo de $d i$ sability studies, composto principalmente por teóricas feministas que vivem a deficiência, e por teóricas que possuem filhos e filhas com deficiência (DINIZ, 2007). Essas pesquisadoras compreendem a deficiência no diálogo com os estudos feministas e de gênero, contrapondo-se à ideia de que a simples supressão das barreiras eliminaria a vivência da deficiência, uma vez que se parte da perspectiva identitária do corpo e, também, do reconhecimento da importância da noção de interdependência como condição humana. Assim, a deficiência é entendida como uma experiência ao mesmo tempo individual, vivida por cada pessoa de um modo diferente e subjetiva, e coletiva, pois é no coletivo que se cria e recria seu entendimento e suas representações ${ }^{1}$.

\section{O corpo de Luciana através do espelho}

Antes de iniciar a análise é preciso fazer algumas considerações no que diz respeito às telenovelas. Telenovelas são produtos televisivos essencialmente ficcionais. Enquanto as produções midiáticas que se apoiam na realidade ${ }^{2}$ supõem uma leitura de correspondência entre o que se descreve e a realidade, os gêneros narrativos ${ }^{3}$ de ficção admitem a criação de um universo que não necessariamente corresponde com o real.

\footnotetext{
1 A representação é entendida como um "processo através do qual os membros de uma cultura fazem uso da linguagem (geralmente definida como qualquer sistema que dispõe de signos, qualquer sistema de significação) para produzir sentido" (HALL, 1997, p.61, tradução nossa). As representações são imagens "[...] que definem sua posição social e as relações que o conjunto de atores sociais estabelecem com um grupo" (MERCIER, 2002, p. 341, tradução nossa).

2 Por realidade entende-se a "[...] qualidade própria dos fenômenos que reconhecemos como independentes de nossa própria vontade (não podemos 'fazê-los desaparecer') e definir o 'conhecimento como a certeza de que os fenômenos são reais e de que possuem características específicas” (BERGER; LUCKMAN, 1995, p.13, tradução nossa).

3 Os gêneros narrativos, segundo Todorov, funcionam como "horizontes de expectativas para os leitores' e como 'modelos de escritura' para os autores" (1978, p.49).
} 
De acordo com Doelker (1982), as ficções utilizam a inevitável relação entre ficção e realidade para ampliar o seu stock de temáticas, e recorrem ao que Aumont (1995) denomina "impressão de realidade". A impressão de realidade não é uma característica exclusiva das telenovelas, mas das obras audiovisuais em geral, pois a ela se deve, fundamentalmente "[...] a riqueza perceptiva dos materiais fílmicos, da imagem e do som" (Ibid., p.148).

Essa propriedade da linguagem audiovisual é o que Jean-Pierre Oudart, citado por Aumont, denomina "efeito do real" (1993, p. 112). Este efeito produzido no público é uma reação psicológica ao que vê, e se produz por meio de analogias entre o real e a imagem representada, seja ela um quadro, uma fotografia, um filme. A partir deste efeito, "o espectador acredita, não que o que vê é o real propriamente, mas, que o que vê existiu, ou pode existir, no real" (Ibid., p. 113, grifos do autor).

Neste contexto, é importante considerar que apesar de as narrativas das telenovelas expressarem uma realidade fictícia, elas se inserem em um contexto social concreto. As representações construídas pelas telenovelas se associam à vida cotidiana e ao contexto de seus telespectadores e telespectadoras. Isto ocorre fundamentalmente nas telenovelas que têm suas bases apoiadas em acontecimentos reais, associados ao contexto de uma sociedade, retificando e atualizando crenças e valores construídos por ela (AYRES, 2009).

Esses tipos de telenovelas geram um vínculo de identificação muito forte com os seus telespectadores pois,

[...] estão associadas a mudanças na vida cotidiana, nos padrões de relacionamentos amorosos e familiares, provocando um processo reflexivo nos espectadores [...] os espectadores comparam sua situação de vida ao que assistem e [...] nesse processo reforçam seus pontos de vista, analisam suas vidas pessoais, o que lhes aconteceu antes, o que vivem naquele momento (ALMEIDA, 2003, p. 22).

Este é o caso de Viver a Vida e da sua abordagem sobre a deficiência. Entretanto, vale lembrar que esta não é a primeira telenovela brasileira a abordar a deficiência. Conforme pesquisa realizada por Silveira (2012), de 1965 até 2009 a Rede Globo tratou a temática em 16 ficções $^{4}$, nos três horários de sua programação destinados a telenovelas inéditas (18h, 19h e 21h). Das dezesseis telenovelas, sete abordaram a deficiência física - sendo a paraplegia o impedimento mais frequente-, dentre as quais, quatro foram protagonizadas por mulheres.

4 Rosinha do Sobrado (1965), Te Contei? (1978), Sol de Verão (1982), Fera Radical (1988), Sexo dos Anjos (1989), Meu Bem Meu Mal (1990), Felicidade (1991), História de Amor (1995), Vira Lata (1996), Torre de Babel (1998), Esplendor (2000), Laços de Família (2000), Desejos de Mulher (2002), América (2005), Caras e Bocas (2009), Cama de Gato (2009). 
No que diz respeito às telenovelas escritas pelo teledramaturgo Manoel Carlos, antes de Viver a vida, o autor já havia incluído por duas vezes a deficiência física em suas histórias. Em 1991, na telenovela Felicidade, a vilã Débora fica paraplégica como castigo por suas maldades, e, em História de amor (1995), o esportista Assunção, fica paraplégico após um acidente de carro. Interessante observar que tanto nestas ficções, como em Viver a Vida, a deficiência é adquirida devido a um acidente.

Para a análise das representações do corpo com paraplegia em Viver a vida, parte-se da perspectiva etnográfica e cinematográfica, aplicando a etnografia de tela que, de acordo com Rial,

[...] apresenta a capacidade de revelar os "espaços sociais" da televisão, a etnografia (de tela ou de audiência) sendo assumida aqui como uma prática de trabalho de campo, fundada em uma prática de coleta e análise de dados extensa e longa, que permite aos pesquisadores atingirem um grau elevado de compreensão do grupo social ou do texto estudado, mantendo uma reflexividade (2004, p.25).

Deste modo, juntamente com a etnografia propriamente dita e aos apontamentos em caderno de campo, realiza-se uma análise da linguagem audiovisual, que supõe a junção de duas linguagens: a linguagem sonora e a linguagem visual.

Ao longo da trama, diversas cenas exploram o corpo com deficiência a partir da história de Luciana (Aline Moraes). Essa história tem claramente três momentos: o período anterior ao acidente; o momento onde Luciana se 'descobre' com uma deficiência; e o período em que ela se reconhece como uma pessoa com deficiência e aceita sua nova condição. Para esta análise foram escolhidas três cenas nas quais Luciana já está paraplégica, porém, no processo de reconhecimento das novas condições de seu corpo.

A primeira sequência selecionada apresenta duas cenas: a primeira é um diálogo entre os irmãos Jorge (J) e Miguel (M), sobre a situação de Luciana; na segunda, Luciana se senta pela primeira vez após o acidente.

No diálogo entre os gêmeos Jorge (namorado de Luciana no momento do acidente) e Miguel (cunhado da moça e um dos médicos que a trata), evidencia-se uma conversa íntima e franca sobre o estado de Luciana após o acidente. A cena se desenvolve no quarto de Jorge, ele está sentado na cama e seu irmão em uma cadeira à sua frente. Os planos médios dos dois personagens, interpretados por Matheus Solano, se intercalam de acordo com a fala. 
M - Olha, Jorge, a fisioterapia é muito importante. É fundamental para a Luciana, ela voltando ou não voltando a andar. Porque é um trabalho que fortalece os músculos, mantém o tônus muscular, ativa a circulação, e também evita o bloqueio articular. Evita que as articulações se deformem. Agora, dai a voltar a andar [...] É muito dificil dizer agora se ela vai se recuperar $100 \%$ ou mesmo se ela vai ter alguma melhora.

$\mathrm{J}$ - Ela até agora não teve nenhuma melhora, né?

M - Aí você está se enganando Jorge. Ela está avançando, está indo super bem na fisioterapia. [...] os progressos nesses casos, são aos pouquinhos [...]

$\mathrm{J}$ - Me sinto tão impotente, sabe?

M - Todos nós sentimos de alguma forma. A gente tem que seguir em frente.

Figura 1: Miguel (esquerda) e Jorge (direita) conversam sobre o estado de Luciana

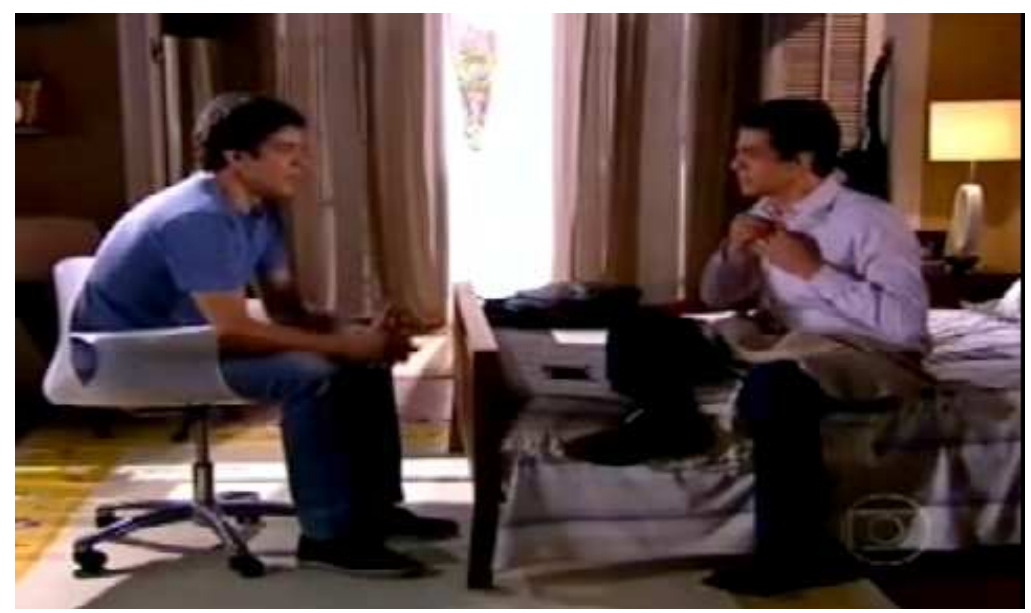

Fonte: VIVER a Vida (Rede Globo/YouTube.)

Apesar de que Luciana não está presente nesta cena, de que seu corpo não é mostrado pela imagem, ele é o centro do diálogo. Ao falar sobre o corpo de Luciana, Miguel e Jorge apresentam dois conceitos de corpo diferentes: o de Jorge, que não é médico, reflete claramente a representação de corpo construído a partir do modelo biomédico, com a ideia da máquina que precisa ser ajustada e que, com os ajustes certos, poderá voltar a 'funcionar' novamente. $\mathrm{O}$ de Miguel, que é médico, e procura mostrar que o corpo é uma estrutura complexa, não uma máquina e, portanto, 'avança' lentamente, sem garantia de uma melhora total. Esta cena possui claramente uma função educativa, ao 
explicar com certo detalhamento a importância da fisioterapia e do cuidado do corpo lesado.

A cena seguinte se inicia com um primeiro plano de Luciana (L) deitada na cama do hospital. $O$ plano se abre. Aparecem, junto à sua cama, do lado esquerdo, uma enfermeira (E), Larissa (F - a fisioterapeuta), Miguel (M), Tereza ( $\mathrm{T}$ - mãe de Luciana), Marcos (M - pai de Luciana), e Jorge (J) que os olha a certa distância da cama.

Figura 2: Luciana se senta pela primeira vez sob o olhar da família

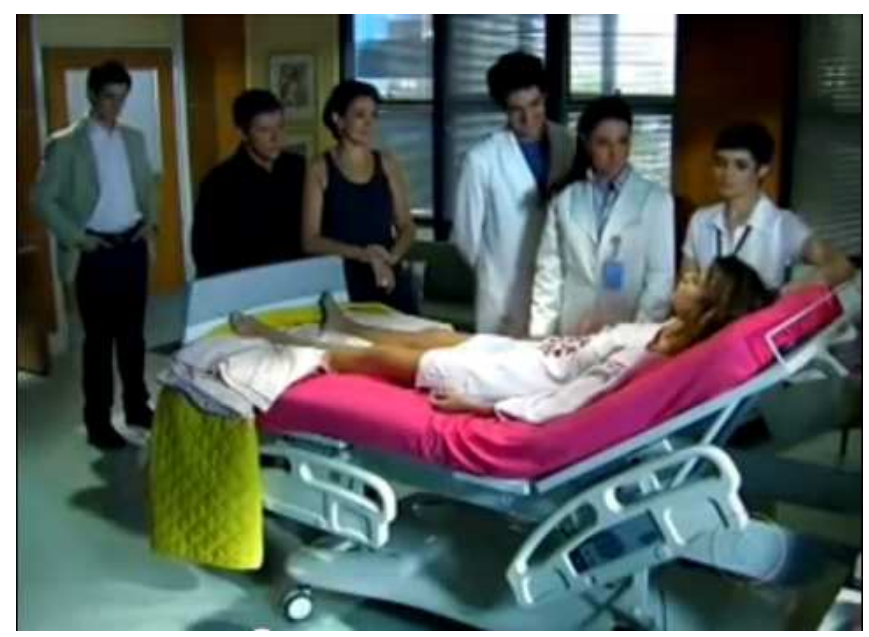

Fonte: VIVER a Vida (Rede Globo/YouTube)

Luciana olha para Larissa (a fisioterapeuta) e o diálogo se inicia:

L - Será que a gente vai conseguir?

F - Se não tentarmos como é que a gente vai saber? Tá na hora de fazer o movimento.

L - Ai meu deus do céu! Olha gente, se eu não conseguir, mil desculpas.

\section{$[\cdots]$}

L - Vamos lá Larissa? Vamos mostrar para eles?

Nesse momento, a música se faz presente, e as pessoas ficam em silêncio, denotando a expectativa. A fisioterapeuta vai até o lado direito da cama, o plano se abre. A câmera se posiciona nos pés da cama, junto ao lado direito. Des- 
te modo, a ação ocorre no centro da imagem, ganhando destaque. $\mathrm{O}$ fato de tanto Luciana como Larissa falarem no plural (nós) é de grande importância, pois quer dizer que elas estão trabalhando juntas e que ambas têm participação no processo de melhoria de Luciana. Aqui evidencia-se uma construção ligada ao modelo social.

Entretanto, vale destacar que, em uma de suas falas, ao referir-se à possibilidade de não conseguir se sentar, Luciana diz "[...] se eu não conseguir, mil desculpas" [grifo nosso]. Neste contexto, essa fala pode querer insinuar que elas (médica e paciente) trabalham juntas, porém, se não houver o 'avanço', seria sua a responsabilidade. Por outras palavras, o erro, o problema, não estaria na medicina nem em seus métodos, mas no paciente. Esta é claramente a perspectiva biomédica.

Antes de iniciar os movimentos, a terapeuta olha nos olhos de Luciana, toca em seu cabelo e pergunta:

\section{F - Posso começar?}

Esta ação, que dura poucos segundos, é central, e reforça o modo como o discurso foi construído ao utilizar o "nós", para se referir às atividades que Luciana realizará. Esses elementos demonstram que nada do que será feito com Luciana será realizado sem seu consentimento. Esta é uma das tantas reivindicações das pessoas com deficiência, defensoras do modelo social: "nada sobre nós sem nós". Esse entendimento redefine o conceito de independência, que não está mais ligado às ações que a pessoa com deficiência pode realizar e, sim, ao controle que ela tem sobre sua vida (MELLO; NUERNBERG, 2012; PALACIOS, 2008).

Uma vez que Luciana confirma com a cabeça, a fisioterapeuta vai avisando-a de cada movimento que fará.

$$
\begin{aligned}
& \text { F - Vamos levantar os joelhos, tirando suas pernas... tudo bem? } \\
& \text { L - Sim. } \\
& \text { F - Agora suas mãos. Agora sua escápula. Tudo bem ai? } \\
& \text { L - Sim. }
\end{aligned}
$$

A fisioterapeuta olha nos olhos de Luciana, segura com uma mão suas costas e com a outra suas pernas.

$$
\text { F - Ok! Vamos? }
$$


AYRES, M. B.; RIAL, C. S.; NUERNBERG, A. H. Luciana no espelho: representações do corpo com...

Luciana hesita por alguns segundos e confirma.

$$
\text { L - Vamos. }
$$

Com um movimento lento a fisioterapeuta senta Luciana na cama.

$$
\begin{aligned}
& \text { L - Isso cansa mais do que pedalar a orla inteira! } \\
& \text { F - No início é difícil mesmo, porque o seu corpo ainda está se } \\
& \text { acostumando [...] }
\end{aligned}
$$

L - Meu Deus do Céu, mas eu tô um pouco tonta. Não, pera aí, tá melhorando.

F - Eu te seguro. Posso me afastar um pouquinho?

L - Não, não, não pode, não! Pera aí, pera ai!! Pera um segundo, meu Deus do Céu! Ai! Calma ai, calma ai! Eu tô com medo!

F - Calma. Confia em mim?

Após duvidar algumas vezes, Luciana fica sentada sozinha, sob o olhar atento dos demais. Escorrem lágrimas pelo seu rosto. Tereza e Marcos estão visivelmente emocionados, mas se mantêm em silêncio, expectantes. Jorge, seu namorado, olha com um pouco de distância, aparentando estar assustado.

L - Como é que eu estou?! - pergunta Luciana, rindo entre lágrimas. Sua pergunta quebra a tensão e todos ali presentes riem.

F - Você conseguiu!

T - Você conseguiu Lu! Parabéns! Que maravilha!

L - Acho que eu quero ficar o dia inteiro assim!

F - Isso é só o começo, viu?

L - Nunca pensei que tão pouco pudesse me deixar tão feliz assim. É como redescobrir o mundo!

Esta segunda parte da cena traz à tona a dimensão subjetiva da vivência. Importante lembrar que esta dimensão somente foi incluída ao modelo social da deficiência após a crítica realizada pelas feministas e pelos estudos feministas e de gênero à primeira geração do modelo (MELLO; NUERNBERG, 2012). 
Figura 3: Luciana se senta pela primeira vez após o acidente

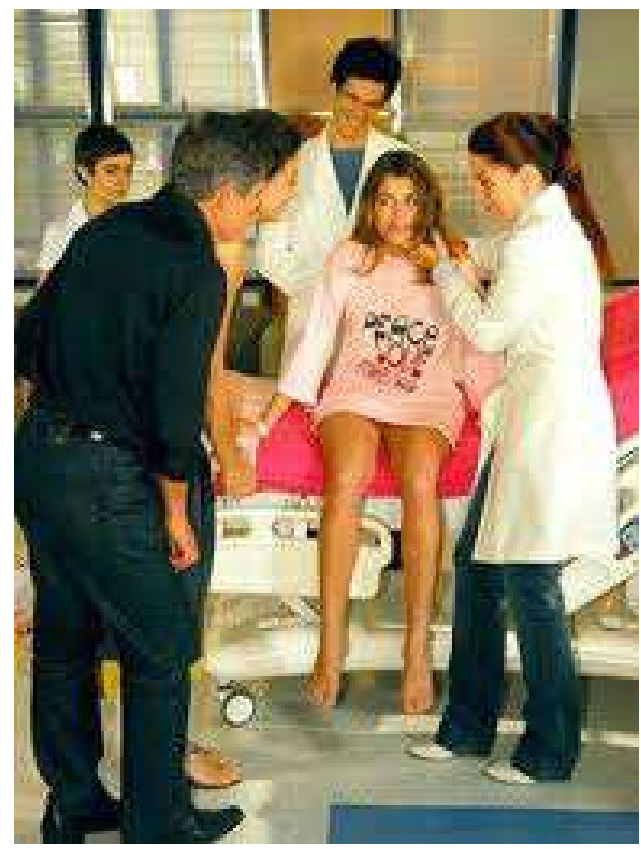

Fonte: VIVER a vida (Rede Globo/ YouTube)

Luciana sente medo, sente cansaço; ao mesmo tempo, está feliz e reconhece o avanço que realizou. "É como redescobrir o mundo", concluiu. Esta afirmação vai ao encontro do que defende Le Breton ao analisar as mudanças que sofremos no corpo ao longo dos anos: "mudar o corpo é mudar a vida" (2011, p. 192).

Ao mesmo tempo, a cena deixa claro o lugar da família, a necessidade do cuidado, do apoio, da contensão. Aspectos também apontados pelas feministas que criticaram a primeira geração do modelo social. Esta mesma linha de argumentação é apresentada quando Luciana, pela primeira vez após o acidente, toma banho em sua casa. A cena transcorre num banheiro completamente adaptado. Podemos ter uma ideia disto pelo plano aberto, que mostra todo o recinto. Luciana está sentada nua, numa cadeira, debaixo do chuveiro. Em frente a ela há um grande espelho. Acompanhando-a estão Tereza (sua mãe) e duas enfermeiras. O diálogo se inicia quando Luciana olha para a mãe e pergunta:

\section{L - Pode lavar meu cabelo?}


AYRES, M. B.; RIAL, C. S.; NUERNBERG, A. H. Luciana no espelho: representações do corpo com...

Tereza tira os sapatos e as enfermeiras saem do banheiro.

T - Você sempre adorou, né filha? Que eu cuidasse do seu cabelo, lavasse, penteasse. [...]

Luciana fica em silêncio, Tereza se cala. O plano se abre mostrando que Luciana se olha no espelho. Todo o seu corpo está refletido ali. O plano seguinte se fecha em seu rosto, denotando tristeza.

$\mathrm{L}$ - Eu perdi tudo o que aprendi na vida, mãe. Parece que eu voltei à infância, só que com a cabeça de adulto. Parece que eu estou diante da morte, mas com sonhos de menina, sabe?

T - Luciana, você tem vocação para ser feliz [...]. E se a vida não está colaborando, o que nós temos que fazer? Buscar em nós mesmas razões para sorrir. Então, olha só esse momento aqui. Não é um momento lindo Luciana? É sim, minha filha! Sabe por quê? Porque você está melhorando! Porque você está superando uma onda ruim.

Um close-up do rosto de Luciana revela suas lágrimas em silêncio, logo o plano se abre. A câmera está posicionada atrás das personagens e o que vemos na tela é o que se reflete no espelho.

T - Agora vou lavar sua cabeça, como nos velhos tempos. Tá bom assim?

L - Sim

T - Que delícia! [beija a cabeça de Luciana e as duas riem].

[...] Posso ligar a água?

L - Que gostoso mãe!

A câmera se aproxima dos rostos de Tereza e Luciana.

$\mathrm{T}$ - Sabe o que me disseram? Que quando a gente está debaixo d'água fica bem perto do nosso anjo da guarda. Então aproveita que você está embaixo d'água. Aproveita esse momento e conversa com seu anjinho [Luciana chora]. Sabe o que você vai pedir para ele? Sabedoria, Luciana! Para você entender tudo o que está acontecendo. Eu tenho certeza de que ele vai te iluminar, ele vai te dar muita força. Você sabe que todo o dia eu converso com meu anjo da guarda e todo dia eu tenho pedido muito por você. 
L - Sabe o que eu vou pedir a ele? Inspiração. Inspiração para poder viver, viver a pesar de tudo. Quem sabe eu não resgato um pouco dessa felicidade mãe.

T - É isso ai minha querida! Meu amor lindo! A gente tem sempre que esperar por dias melhores.

L - Queria tanto te fazer um carinho, mãe.

Tereza pega a mão de Luciana e a passa suavemente pelo seu rosto. As duas choram. A música surge acompanhando o barulho da água do chuveiro. A câmera se distancia, lentamente, registrando a cena de lado. Vemos todo o corpo de Luciana nu. Ela está sentada na cadeira debaixo do chuveiro e é abraçada por Tereza, que está descalça, porém, vestida.

Figura 4: Tereza dá banho em Luciana

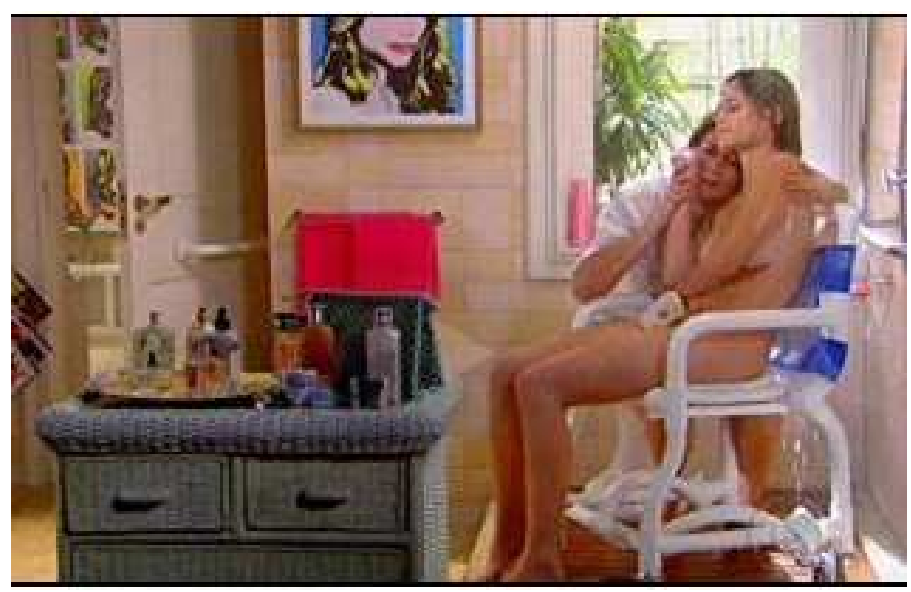

Fonte: VIVER a vida (Rede Globo/YouTube)

O primeiro aspecto que deve ser considerado ao analisarmos esta cena é a história da personagem, pois como afirma Le Breton "a imagem do corpo não é um dado objetivo, é um valor que resulta essencialmente da influência do entorno e da história pessoal do sujeito" (2011, p.217, tradução nossa).

Luciana é uma jovem bonita, rica, saudável, que trabalhava como modelo. Em sua primeira viagem internacional a trabalho, sofre um acidente de trânsito e fica paraplégica. Antes do acidente, Luciana era muito vaidosa e exaltava sua beleza e juventude em suas falas e ações. Entre estas falas podemos citar um diálogo entre ela e Helena, no primeiro capítulo da telenovela. As modelos se encontram na rua e Luciana diz: 
L - [...] to lá encima no topo fazendo sucesso [...] Você está sabendo que essa cara, essa cara que Deus me deu está entre as 20 mais fotografadas do Brasil, só no ano passado, Helena?

Luciana, antes do acidente via o sucesso como uma realidade para toda sua vida, e este êxito estava relacionado diretamente à sua imagem, à sua beleza e juventude; por outras palavras, ao seu corpo. Corpo lindo, dado, segundo ela, por Deus. Ou seja, Deus seria, para ela, o 'responsável' pelo seu sucesso.

Tendo em vista a trajetória da personagem, a cena do banho ganha novos significados, pois esta é a primeira vez que a moça se encontra, literalmente, diante da nova condição do seu corpo. A primeira reação de Luciana é dizer que já não pode realizar tudo o que aprendeu, como se o seu corpo não tivesse mais serventia, e isto a faz sentir diante da morte. Nesta percepção, se evidencia a concepção biomédica do corpo: para existir o ser humano precisa de um corpo e este corpo deve ter todas as faculdades necessárias para realizar a interação entre o 'eu' e o mundo. Esta é a forma como ela avalia seu reflexo no espelho. Já o público vê um corpo lindo, magro, jovem, porém, sem movimento. Sem movimento para realizar ações de todo tipo, desde lavar o cabelo até acariciar a mãe. No entanto, estas ações podem ser feitas com a ajuda de outras pessoas, partindo das decisões tomadas por Luciana. Assim, sua mãe lava seu cabelo ou pega sua mão e acaricia o seu rosto, respondendo a um pedido da moça.

Os curtos silêncios e as lágrimas têm grande transcendência na cena, mostrando o desconsolo da personagem, e a dificuldade de reconhecer-se na nova condição de seu corpo. Esta cena parece representar um rito de passagem: a água que limpa, que purifica, que 'conecta' a moça com os anjos, que a ajuda a sair do estado emocional no qual se encontra. Uma passagem que não é feita sozinha, ela está acompanhada de sua mãe, marcando assim a ideia de renascimento. Luciana vive um momento de reconhecimento e, nele, começa a redescobrir novos prazeres, e a dar novos sentidos às suas vivências, entendendo que a felicidade não está necessariamente ligada ao corpo.

Quando Tereza afirma: “[...] você tem vocação para ser feliz”, está defendendo a possibilidade de se ter felicidade independente de qualquer condição física e quebrando com a concepção clássica de corpo, na qual ele é o centro do ser humano. Tereza inclusive a incita a conversar com o seu anjo da guarda.

Há, ao longo da novela, uma recorrente citação a Deus, aos anjos, ou a outras forças, colocando-as como mais poderosas do que o ser humano; sendo elas capazes de ajudar a moça a sair do estado no qual se encontra. Foi Deus quem lhe deu o corpo saudável e jovem, foi Ele quem a colocou no ônibus e permitiu que o acidente ocorresse, e agora será Deus ou os anjos que a ajudarão a dar sentido à sua vivência. Este é um claro posicionamento da ficção com relação não só à deficiência, mas à vida. 
Finalmente, vale observar outros detalhes da cena que são reveladores. Primeiro, Luciana desde o início está nua, sentada na cadeira já debaixo do chuveiro. O relato omite os momentos prévios ao banho. Não sabemos como ela chegou até ali, como tirou a roupa, como sentou na cadeira. O público simplesmente a vê sentada, como se o processo que ela teve que passar não fosse importante. Certamente uma pessoa com paraplegia necessitaria de ajuda em todo esse processo. Esta exclusão, que não ocorre somente nesta cena, mas em outras cenas da telenovela, deixa dúvidas: por que estes momentos, que fazem parte da vida cotidiana de uma pessoa com deficiência, são excluídos? O que se está querendo 'omitir' ou 'esconder'? Mostrar esses momentos em que a personagem é amparada, ajudada por outras pessoas, não é importante para a representação?

Segundo, o fato de que ela esteja completamente nua desde o início, e que Tereza a banhe estando toda vestida, traz consigo a noção de fragilidade. Mas esta fragilidade, por um lado, não implica uma avaliação negativa do corpo. Não há, em nenhum momento, uma avaliação depreciativa ou que mostre que o corpo de Luciana já não tem nenhum valor ou vale menos que antes, apesar de que a personagem possa se sentir assim. Por outro lado, esta fragilidade está relacionada ao fato de que Lucina está ali completamente exposta e desprotegida e precisa confiar e se entregar às pessoas que a cercam, neste caso, sua mãe. A relação das pessoas com deficiência física e seus cuidadores/ cuidadoras é central, pois nesta relação entram em jogo questões como a intimidade, os pudores, a confiança. Todos estes elementos aparecem expostos na cena de modo sutil, mas são reforçados ao longo da telenovela por outras cenas e diálogos.

\section{Quais são as representações do corpo de Luciana?}

É preciso partir do entendimento de que toda telenovela é uma ficção e que o seu principal objetivo é entreter e não documentar. Contudo, muitas vezes, parte de temáticas reais que retomam o seu contexto e, ao abordá-las, é inevitável estabelecer 'pontes' entre a ficção e a realidade. Ao estabelecer este diálogo sobre problemas sociais, as telenovelas se tornam um espaço público de discussão, estimulando a reflexão e revisão de representações.

No caso específico de Viver a vida, houve o claro objetivo de abordar a deficiência, discutir sobre ela, incentivando a reflexão. Para este artigo foram analisadas três cenas da telenovela (referentes ao momento em que Luciana se descobre deficiente), buscando responder a pergunta: quais são as representações do corpo com paraplegia apresentadas por Viver a Vida? Todas as cenas fazem parte do primeiro momento após o acidente. Ao longo do relato há inúmeras cenas que fazem referência ao corpo da jovem, porém, a escolha destes trechos responde ao fato de que neste período ocorre o primeiro 'choque' e o início da adaptação, evidenciando o posicionamento da ficção com relação ao conceito de corpo com deficiência física. 
Da análise pode-se concluir que não há uma única representação do corpo com paraplegia no contexto analisado. As representações não são unívocas, lineares e estáticas, elas se adaptam a cada cena. Por exemplo, na cena em que Luciana toma banho, o corpo aparece o tempo todo relacionado à outra coisa: à alma, à mente, aos sentimentos, à subjetividade, etc. Já na cena em que Miguel e Jorge falam sobre Luciana, foca-se no corpo em si, na discussão entre o conceito de corpo máquina e o corpo como algo mais que uma máquina, como um mediador entre eu e o mundo. Nesta cena, há a encenação de um possível diálogo entre o modelo médico e o modelo social da deficiência.

Pôde-se observar-se ainda que, tanto o modelo social como o modelo médico, e os seus respectivos conceitos de corpo, estão presentes nas três cenas, sobrepondo-se e constituindo-se mutuamente. Assim, as representações do corpo com deficiência, como uma balança, pendem para um lado e para o outro ao longo do relato. Nas três cenas o corpo é apresentado como principal fonte de impedimentos, sejam eles físicos ou emocionais, o que faz a balança pender para o modelo médico da deficiência. No entanto, esta telenovela estabelece - apesar de não fazê-lo explicitamente - um diálogo com os fundamentos ideológicos que balizam a Convenção sobre os Direitos das Pessoas com Deficiência, ratificada em 2008, pouco antes de sua veiculação. É possível reconhecer esse diálogo não só no conceito de corpo, mas também na noção de cuidado, de subjetividade da vivência da deficiência, e na clara intenção de não desvalorizar essas pessoas, não hostilizá-las, e sim incluí-las no ambiente. Este aspecto faria a balança pender para o modelo social da deficiência.

Igualmente, o corpo de Luciana não é apresentando como um corpo sem serventia. Apesar de ter uma lesão, este corpo ainda é o mediador entre ela e o mundo. É um corpo vivo, que sente, se emociona, produz. Ao abordar o corpo deste modo, a telenovela se distancia do entendimento do corpo do modelo médico (que negligencia o sujeito e sua história), e se aproxima do modelo social (fundamentalmente a segunda geração, muito influenciada pelo movimento feminista), que reivindica a compreensão da experiência do corpo lesado e a subjetividade da experiência de viver com deficiência.

A decisão sobre as ações a serem realizadas é um aspecto importante nas representações do corpo com deficiência física nesta ficção. Tanto na cena em que Luciana se senta pela primeira vez, como na que toma banho, é ela quem vai definindo as ações, ela aceita que a terapeuta a ajude a sentar-se, é ela quem pede à mãe que lave seu cabelo, e assim por diante. Como dito anteriormente, este é um aspecto muito relevante para o movimento das pessoas com deficiência, visto que elas defendem que a independência está ligada ao controle que elas têm sobre suas vidas, e não a quão longe podem chegar (PALACIOS, 2008).

Nas cenas analisadas revela-se o entendimento de que o corpo não é uma máquina. Por meio de Luciana, o ser humano é mostrado como alguém que possui limites, que há coisas que não podemos resolver ou alterar. Isto fica cla- 
ramente exposto quando Tereza incita Luciana a que fale com os anjos. Nessa perspectiva, Luciana é uma humana como qualquer outra e, portanto, não poderá sair da situação na qual se encontra por mero desejo. Isto explicaria a razão pela qual recorre a 'seres superiores', que poderiam ajudá-la a 'adaptarse' à sua vivência. Lembrando que 'adaptar-se ' não significa necessariamente sair da situação.

Finalmente, vale lembrar que o corpo com paraplegia mostrado nesta telenovela não é 'qualquer corpo'. É o corpo de uma jovem mulher, que segue os padrões de beleza 'tradicionais': magra, branca, com cabelo castanho claro. Estes padrões de beleza se reforçam com a profissão da personagem: modelo. Talvez o padrão de corpo tenha sido escolhido propositalmente, como uma forma de mostrar os dois polos: primeiro, um corpo considerado pela sociedade como 'perfeito', como um 'modelo a ser seguido', e num segundo momento, um corpo entendido a partir do modelo médico, largamente divulgado na sociedade, como 'imperfeito'. Entretanto, ao longo do relato vai se evidenciando que este corpo com deficiência não é 'imperfeito', é uma condição, situação diferente. É um corpo que produz, que sente, que pensa, que pode amar e ser amado, etc. De qualquer forma, ainda é preciso fazer uma análise mais aprofundada sobre gênero e raça, pois em nenhum momento são mostradas na telenovela pessoas pretas ou homens com deficiência.

Do mesmo modo, é necessário analisar com mais detalhamento a questão da classe social. Luciana é uma jovem rica e tem acesso a todo tipo de equipamento e profissional que possa contribuir com sua melhoria. Se este aspecto, por um lado, promove a divulgação de equipamentos, tecnologias disponíveis; por outro, contribui para idealizar uma forma de viver a deficiência, como se a vivência fosse mais simples, mais fácil, menos sofrida por se ter um banheiro adaptado, um carro adaptado, uma sala de exercícios ou uma fisioterapeuta disponível 24 horas por dia, etc. A esta idealização deve-se acrescentar o fato de que, tanto nas cenas analisadas como em outras cenas da telenovela, são omitidos alguns dos momentos em que Luciana precisaria de ajuda específica para realizar ações como trasladar-se, vestir-se, etc., ou momentos de grande dor física.

Tanto o acesso ilimitado a tecnologias e serviços, que não é uma realidade para a maior parte das pessoas com deficiência física, como a exclusão de momentos em que a pessoa precisa de ajuda, ou vivencia a dor, que são parte da vida diária das pessoas com deficiência física, podem apontar para uma representação idealizada. E, nesta idealização, Luciana deixa de ser vista como 'vítima' e passa a ser vista como 'heroína', remarcando aqui uma narrativa de superação que se afasta da realidade vivida por estas pessoas, e da noção de deficiência como modo de vida.

Assim, as representações do corpo com paraplegia em Viver a vida, levam a pensar numa abordagem mais ampla da deficiência física, não entendendo a pessoa como um mero corpo, como uma 'máquina com defeito', mas um ser 
amplo e complexo. Ao divulgar a deficiência de um modo mais abrangente a telenovela pode contribuir com a reflexão sobre os 'fantasmas' da representação, construída e expandida largamente, no tempo e no espaço, a partir do modelo médico; e para a divulgação de ideias que se aproximam do modelo social, ainda pouco conhecido no Brasil.

\section{Referências}

ALMEIDA, H. Buarque de. Telenovela, consumo e gênero: "muitas mais coisas". Bauru: EDUSC, 2003.

AUMONT, Jacques. A estética do filme. Campinas, São Paulo: Papirus, 1995. . A imagem. Campinas, São Paulo: Papirus, 1993

AYRES, Melina de la Barrera. Telenovela, entretener o educar. Cuadernos del CLAEH: Revista uruguaya de ciencias sociales. Uruguai, Ano 32, n. 98, p.55-68, 2009, .

BERGER, Peter L.; LUCKMANN, Thomas. La Construcción Social de la Realidad. Buenos Aires: Ed. Amorrortu, 1995.

BRAH, A. Diferença, diversidade e diferenciação. Cadernos Pagú, n.26, p. 329 - 376, jan./jun. 2006. Disponível em: <http://www.scielo.br/pdf/cpa/n26/30396.pdf> Acesso em: 10 out. 2013.

DINIZ, D. O que é deficiência. São Paulo: Brasiliense, 2007.

DOELKER, Christian. La realidad manipulada: radio, TV, cine y prensa. Barcelona: Ed. Gilli, 1982.

HALL, S. Representation: Cultural representations and signifying practices. London: Sage, 1997.

LE BRETON, D. Antropologie du corps et modernité, $6^{\mathrm{a}}$ Ed., Paris: Presses Universitaires de France, 2011.

MELO, Anahi Guedes de; NUERNBERG, Adriano Henrique. Gênero e deficiência: interseções e perspectivas. Revista de Estudos Feministas, Florianópolis, n. 20, p. 635-655, set./dez. 2012.

MERCIER, M; Impact des représentations sociales du handicap sur le stress vécu par les personnes handicapées et leur famille. In: SERVAIS, Paul; STEICHEN, Robert. (Orgs). Handicap: Accueil, solidarité et accompagnement en famille. Belgique: Bruylant-Academia S.A, 2002. p. 177- 197.

OLIVER, M. Understanding disability: from theory to practice. United Kingdom: Palagrave Macmillan, 2009.

ORTEGA, F. Deficiência, Autismo e Neurodiversidade. Ciência \& Saúde Coletiva, n. 14, p. 67-77, 2009. 
PALACIOS, A. El modelo social de discapacidad: orígenes, caracterización y plasmación en la Convención Internacional sobre los Derechos de las Personas con Discapacidad. Madrid: Grupo Editorial Cinca, 2008.

RIAL, C. Antropologia e mídia: breve panorama das teorias de comunicação. Revista Antropologia em primeira mão. Florianópolis, Programa de Pós Graduação em Antropologia Social, n. 74, p.4- 67, 2004.

SILVEIRA, B. Rocha. Entre a vitimização e a divinização: a pessoa com deficiência em Viver a vida. 2012, 148 f. Dissertação (Mestrado em Comunicação). Pontifícia Universidade Católica do Rio Grande do Sul, Porto Alegre, 2012.

VIVER a vida. Telenovela de Manoel Carlos. Direção: Jayme Monjardim; Fabrício Mamberti. [S.1], Rede Globo, transmissão de 14 set. 2009 a 14 mai. 2010. [209 episódios]. Disponível em: <www.globo.com/viveravida. $>$ Acesso em: mai. 2013.

TODOROV, Tzvetan. Os gêneros do discurso. São Paulo: Martins Fontes, 1978.

Submissão em: 29/10/2013

Revisado em: 05/03/2014

Aceite em: 05/04/2014

Melina de la Barrera Ayres é Doutoranda Interdisciplinar em Ciências Humanas (UFSC), sendo bolsista financiada pela CAPES, e bolsista de Doutorado Sanduíche CAPES/COFECUB. Mestre em Jornalismo (UFSC-2009), Bacharel em Comunicação Social - Habilitação Jornalismo (Universidade Católica do Uruguai - 2006). Endereço para correspondência: Núcleo de Antropologia Audiovisual e Estudos da Imagem, Universidade Federal de Santa Catarina, Centro de Filosofia e Ciências Humanas, Campus Universitário - Florianópolis/SC, Brasil. CEP 88040-970. E-mail: melina.ayres@gmail.com

Carmen Silvia Rial é Doutora em Antropologia Universidade de Paris V, professora do Departamento de Antropologia, atuando nos PPG's em Antropologia Social e Interdisciplinar em Ciências Humanas da Universidade Federal de Santa Catarina, pesquisadora 1C do CNPQ. E-mail: rial@cfh.ufsc.br

Adriano Henrique Nuernberg é Doutor em Ciências Humanas (UFSC), professor do Departamento de Psicologia, atuando na Graduação e Pós-graduação (UFSC).

E-mail: adrianoh@cfh.ufsc.br 